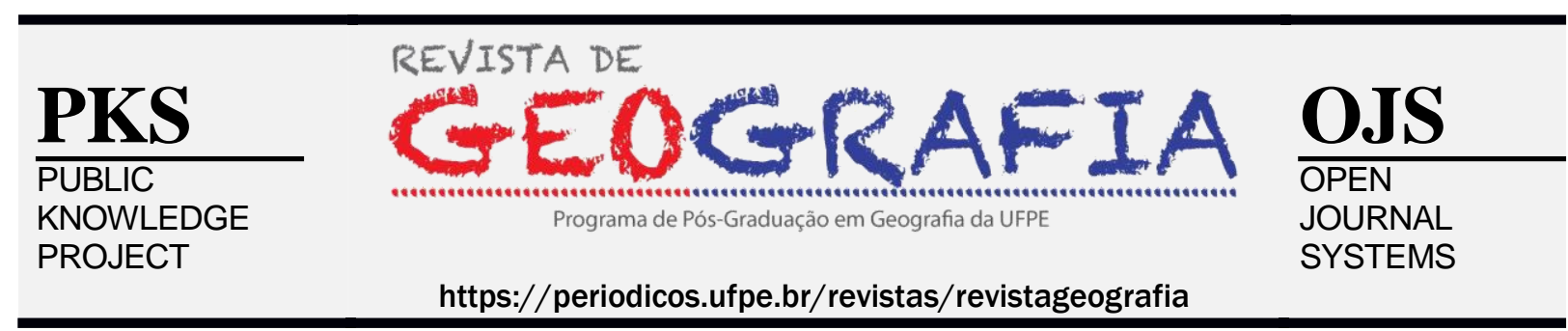

\title{
A URGÊNCIA DE POLÍTICAS PÚBLICAS DE EDUCAÇÃO NA MICRORREGIÃO DA MATA MERIDIONAL PERNAMBUCANA
}

\author{
Gustavo de Souza Barbosa ${ }^{1}$
}

\begin{abstract}
${ }^{1}$ Doutorando do Programa de Pós-graduação e Pesquisa em Geografia da Universidade Federal do Rio Grande do Norte. Mestre em Geografia pela Universidade Federal de Pernambuco. Professor de Ensino Básico, Técnico e Tecnológico do Instituto Federal de Educação, Ciência e Tecnologia de Pernambuco - IFPE, Campus Recife. E-mail: gustavosouza@recife.ifpe.edu.br.
\end{abstract}

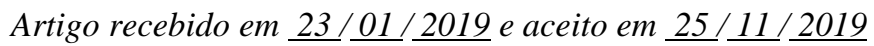

\begin{abstract}
RESUMO
A educação tem se tornado cada vez mais um elemento chave para o desenvolvimento socioeconômico, reflexo disto tem sido sua valorização pelo Estado mediante políticas públicas específicas, como tem feito o estado de Pernambuco. As políticas públicas, por sua vez, inserem-se em territórios complexos e heterogêneos, neste sentido, o artigo tem como objetivo geral discutir os desafios de uma política pública estadual quanto ao quadro educacional da Microrregião da Mata Meridional Pernambucana e, como objetivos específicos, visa-se discutir a relevância da educação atualmente; identificar as metas estaduais voltadas ao setor para os próximos anos e descrever o quadro microrregional de educação frente ao estado de Pernambuco e ao Brasil. A metodologia adotada baseou-se na pesquisa bibliográfica em autores específicos que abordam a relação educação-desenvolvimento e no levantamento documental das metas estaduais para a educação e de dados relativos ao setor nas escalas microrregional, estadual e nacional. Parte-se da hipótese que a melhoria da educação na Microrregião mostra-se bastante desafiadora para as metas pernambucanas e conclui-se que o quadro da educação microrregional como um todo apresenta índices aquém da situação educacional brasileira e pernambucana, tornando-se necessária, além de uma política pública de educação, uma política pública particular voltada às especificidades locais.
\end{abstract}

Palavras-chave: Educação; Metas; Pernambuco; Mata Meridional Pernambucana.

\section{THE URGENCY OF PUBLIC POLICIES OF EDUCATION IN THE MICROREGION'S MATA MERIDIONAL, PERNAMBUCO, BRAZIL}

\begin{abstract}
Education has become increasingly a key element for socioeconomic development, a reflection of which has been its valorization by the State through specific public policies, as has been done in Pernambuco. Public policies, in turn, fall into complex and heterogeneous territories. In this sense, the article has the general objective of discussing the challenges of a state public policy regarding the educational framework of the Microregion's Mata Meridional Pernambucana. As specific objectives, aims to discuss the relevance of education today; identify the state goals for the sector for the coming years and describe the microregional framework of education facing the state of Pernambuco and Brazil. The methodology adopted was based on bibliographical research in authors that address the education-development relationship and the documentary survey of the state goals for education and data related to the sector at the microregional, state and national scales. It is hypothesized that the improvement of education in the Microregion is very challenging for the Pernambuco goals and it is concluded that the microregional education as a whole presents indices below the Brazilian and Pernambuco educational situation, making it necessary, besides of a public education policy, a particular public policy focused on local specificities.
\end{abstract}

Keywords: Education; Goals; Pernambuco. Mata Meridional Pernambucana.

Barbosa, 2019 ISSN 0104-5490 


\section{INTRODUÇÃO}

A educação cada vez mais tem assumido relevante papel na sociedade contemporânea, o que pode ser observado a partir da maior preocupação da sociedade e do Estado, sobretudo, no que tange à oferta e qualidade do serviço promovido. Quanto à esfera estatal, pode-se observar o maior enfoque dado à educação a partir da criação de indicadores a serem atingidos, como os que se referem ao ensino fundamental, e o estabelecimento de projetos de longo prazo com metas específicas para a educação, a exemplo do promovido pelo estado de Pernambuco em 2014. Tanto os indicadores quanto os projetos, por sua vez, envolvem recortes territoriais e sociais diversos, cujas metas propostas podem mostrar-se já ultrapassadas, possíveis de serem alcançadas ou dificilmente atingidas.

Tomando-se como ponto de partida a importância da educação para o desenvolvimento socioeconômico, a sua relevância para o estado de Pernambuco a partir da elaboração de metas específicas num projeto mais abrangente e o quadro educacional de um recorte territorial do estado pernambucano, a Microrregião da Mata Meridional, objetiva-se no presente texto discutir os desafios de uma política pública estadual quanto ao quadro educacional específico desta Microrregião considerando-se a discussão quanto à relevância da educação na atualidade; a identificação das metas estaduais específicas ao setor para os próximos anos e a descrição do quadro microrregional de educação frente ao estado de Pernambuco e ao Brasil.

A partir da pesquisa bibliográfica em autores específicos que abordam a relação entre educação e desenvolvimento e do levantamento documental das metas estaduais para a educação e de dados relativos ao setor nas escalas microrregional, estadual e nacional, parte-se da hipótese que a melhoria da educação na esfera da Microrregião mostra-se bastante desafiadora para as metas propostas pelo estado de Pernambuco, estas que necessitam ser alcançadas mediante o maior valor da educação no contexto atual.

Como forma de análise do tema proposto, o texto encontra-se estruturado em três itens. Inicialmente será tratada a relevância da educação na atualidade mediante as novas demandas econômicas e sociais, no segundo momento, a partir da análise de um plano de desenvolvimento estadual serão apresentados os projetos específicos à educação no estado de Pernambuco e, por fim, são apresentados os valores referentes aos aspectos educacionais em diferentes escalas. Nas considerações finais busca-se satisfazer a hipótese proposta a partir da reconstrução do quadro educacional da Microrregião da Mata Meridional Pernambucana e sua possibilidade de 
alcance frente às metas propostas pelo estado, assim, sendo capaz, ou não, de promover o desenvolvimento econômico e social em seu território.

\section{A IMPORTÂNCIA DA EDUCAÇÃO PARA O DESENVOLVIMENTO}

O avanço tecnológico tem promovido cada vez mais novos padrões de produtividade e competitividade, neste contexto, a educação surge como um componente essencial das estratégias de desenvolvimento ${ }^{1}$, ganhando cada vez mais centralidade nas pautas governamentais e levando os diferentes Estados, mediante suas características históricas e peculiaridades, a promoverem reformas nos seus sistemas educacionais para torna-los mais eficientes e equitativos (MELLO, 1991) quando, independentemente das suas singularidades passam, ou deveriam passar, a destinar importantes recursos à produção de conhecimento e tecnologia e à formação de pessoas mais qualificadas para o exercício profissional.

Segundo Saviani (2010 apud FAVARO; TUMOLO, 2016) o investimento em educação deve ser considerado o elemento central para promoção do desenvolvimento, visto que propicia à sociedade benefícios em todas as esferas a partir da maior distribuição de renda, dos estímulos para a igualdade social, aumento dos empregos e dos salários (inclusão social) e estímulo ao consumo, este que, ativa a produção industrial e agrícola e o comércio, gerando mais empregos, aumentando a competitividade empresarial e a arrecadação de impostos, os quais o Estado pode direcionar para o setor de infraestrutura e para os programas sociais, promovendo, assim, o desenvolvimento geral do território.

A educação é na contemporaneidade não só tida como uma necessidade econômica mediante a revolução tecnológica, mas como um meio em si mesma de melhoria da qualidade de vida das pessoas e, concomitantemente, sua inserção frente às novas demandas que se apresentam. O desenvolvimento tecnológico, mediante a automação industrial, por exemplo, traz não só funções manuais que podem substituir o homem, pelo contrário, "exigem" a maior presença e competência humana para o exercício de funções em nível superior. Organizar a produção, prevenir falhas, garantir a qualidade são demandas que requerem raciocínio analítico, habilidade e rapidez na tomada de decisões, o que, por sua vez, remete para a escola a reponsabilidade não só de propiciar o domínio instrumental da linguagem, da matemática e de

\footnotetext{
${ }^{1}$ Considera-se aqui o desenvolvimento como um conceito qualitativo, mais amplo, que engloba a melhoria do bem-estar socioeconômico de uma população a partir da redução da pobreza, do desemprego e da desigualdade e da melhoria das condições de saúde, alimentação, moradia e educação.
} 
conteúdos específicos, mas, a construção de habilidades cognitivas como a compreensão, o pensamento analítico e abstrato e a flexibilidade de raciocínio diante de novas situações problemas (MELLO, 1991). O papel da escola na atualidade, portanto, consolida-a como uma instituição de promoção do desenvolvimento humano em suas mais amplas e diversas capacidades.

Ao passo que a nova dinâmica contemporânea institui desafios para o homem em termos práticos, como a necessidade de adquirir conhecimentos diferenciados para o exercício profissional, institui também desafios no campo educacional quanto à formação de competências sociais, como a capacidade de liderança, de iniciativa, de tomar decisões, de ser autônomo no trabalho e de ter habilidade de comunicação (MELLO, 1991). A educação, consequentemente, assume outras dimensões, cada vez mais relevantes e complexas.

Diante das demandas atuais, segundo Mello (1991), o debate e a formulação de políticas educacionais, tem firmado alguns consensos: (1) a educação passa a ocupar definitivamente lugar central e articulado na pauta das macro políticas do Estado como elemento importante para a qualificação dos recursos humanos; (2) a educação torna-se parte indispensável do esforço para tornar as sociedades mais igualitárias, solidárias e integradas; (3) adquirir conhecimentos básicos e formar habilidades cognitivas são condições indispensáveis para que as pessoas consigam conviver de forma produtiva num ambiente saturado de informações e sejam capazes de processá-las e continuar aprendendo e; (4) o conhecimento, a informação e uma visão mais ampla dos valores são a base para a cidadania organizada em sociedades plurais, cambiantes e cada vez mais complexas, como é o caso brasileiro.

O novo padrão de desenvolvimento e as novas responsabilidades atribuídas à educação inserem-se em diferentes escalas, da internacional à nacional, nesta torna-se cada vez mais complexa diante das singularidades de cada recorte político-administrativo interno aos países. As políticas educacionais, neste sentido, apresentam maior probabilidade de êxito quando pensadas por escalas inferiores ao Estado-nação que tendem a melhor conhecer suas demandas, projetos e necessidades territoriais nos mais diferentes recortes.

\section{AS METAS PARA A EDUCAÇÃO EM PERNAMBUCO}

Diante das novas demandas promovidas pela sociedade contemporânea permeada pelo desenvolvimento tecnológico e pela promoção do conhecimento, a educação, conforme pôde ser observado, tem se configurado como um setor chave não só para o crescimento econômico

\begin{tabular}{lll}
\hline Barbosa, 2019 & ISSN 0104-5490
\end{tabular}


mas para a promoção do desenvolvimento social e redução das desigualdades, estabelecendose como uma das preocupações futuras da sociedade desde o início do século $\mathrm{XXI}^{2}$. O estado de Pernambuco, em consonância com o novo quadro socioeconômico instituído, também inseriu entre suas metas a melhoria quanto à educação e ao conhecimento num projeto de tempo mais longo elaborado em 2014, intitulado "Pernambuco 2035".

Considerada a principal parte do plano "Pernambuco 2035", a "Estratégia de Desenvolvimento de Pernambuco e Carteira de Projetos Públicos”, (PERNAMBUCO, 2014) elenca os planos de responsabilidade direta e dominante do setor público e apresenta, além de uma breve análise da evolução socioeconômica, ambiental e institucional do estado nas últimas décadas, as concepções norteadoras, os eixos estratégicos, as áreas prioritárias de atuação e os projetos estruturantes quanto às ações do governo na construção do futuro do estado. A partir deste documento foram selecionados projetos, objetivos e abrangência territorial vinculados especificamente ao aspecto educacional estadual como forma de aproximação entre o quadro planejado e a realidade concreta da educação pernambucana em uma das suas microrregiões.

Seguindo a tendência global de maior necessidade de formação de recursos humanos qualificados e maior promoção do conhecimento como fatores relevantes à promoção do crescimento econômico e desenvolvimento social, a "Estratégia de Desenvolvimento de Pernambuco e Carteira de Projetos Públicos" do Plano "Pernambuco 2035" (PERNAMBUCO, 2014) considera a educação como um elemento central na competitividade econômica, fortalecedor da tolerância e da democracia e condicionante para a promoção da igualdade e de oportunidades sociais ${ }^{3}$. Neste sentido, configura-se como um conjunto articulado e convergente de ações voltadas para o aumento do nível de escolaridade e da taxa de escolarização dos jovens no ensino médio, para a melhoria da qualidade do ensino em todos os níveis e para a intensificação da formação do capital humano com qualificação profissional em larga escala.

O processo de melhoria da educação proposto na Estratégia (PERNAMBUCO, 2014) operacionaliza-se através de sete projetos organizados e coordenados principalmente pela Secretaria de Estadual de Educação, a maioria deles com data de início prevista para 2015 e término em 2020, exceto o projeto de implementação de escolas de educação integral nos

\footnotetext{
${ }^{2}$ No Brasil, especificamente, entre 2004 e 2005, num projeto chamado "Brasil 3 Tempos" que estudou cenários para o país em 2007, 2015 e 2022, dentre as cinco questões consideradas de maior importância, duas relacionavamse à qualidade e universalização da educação básica, assim como, questões adicionais de maior relevância quanto ao conhecimento, referiam-se, dentre outras, à ampliação do ensino superior (STEINER, 2006).

${ }^{3}$ Steiner (2006, p. 75) ressalta que "no mundo contemporâneo, o conhecimento é o maior gerador de riqueza, [...] que é fundamental que o cidadão possa usar o conhecimento de forma útil e produtiva. Portanto, educação de qualidade em todos os níveis é essencial".
} 
últimos anos do ensino fundamental, que estava programado para iniciar-se em 2016 e ser concluído em $2021^{4}$. Os projetos eram direcionados para populações em idade escolar específica, da pré-escola ao ensino superior, e abrangia todo território estadual em consonância com as peculiaridades locais, a exemplo das vocações econômicas (Quadro 1).

\section{Quadro 1 - Projetos por Área de Resultado-Educação e Conhecimento, 2014}

\begin{tabular}{|c|c|c|}
\hline Projeto & Objetivo(s) & Abrangência territorial \\
\hline $\begin{array}{l}\text { Ampliação da oferta, do } \\
\text { acesso e da qualidade na } \\
\text { educação infantil. }\end{array}$ & $\begin{array}{l}\text { Aumentar o percentual de crianças } \\
\text { de } 0 \text { a } 5 \text { anos que frequentam creches } \\
\text { e pré-escolas. }\end{array}$ & $\begin{array}{l}\text { Todo o estado de acordo com o } \\
\text { tamanho da população infantil da } \\
\text { faixa etária e com as carências } \\
\text { diferenciadas no território. }\end{array}$ \\
\hline $\begin{array}{l}\text { Melhoria da qualidade do } \\
\text { ensino fundamental. }\end{array}$ & $\begin{array}{l}\text { Elevar o percentual de alunos com } \\
\text { aprendizado adequado em português } \\
\text { e matemática no } 5^{\circ} \text { e } 9^{\circ} \text { ano; Reduzir } \\
\text { a distorção idade-série. }\end{array}$ & $\begin{array}{l}\text { Todo o estado de acordo com o } \\
\text { tamanho da população infantil de } \\
6 \text { a } 14 \text { anos e com as carências } \\
\text { diferenciadas no território }\end{array}$ \\
\hline $\begin{array}{l}\text { Implementação das } \\
\text { escolas com educação } \\
\text { integral nos anos finais do } \\
\text { ensino fundamental II. }\end{array}$ & $\begin{array}{l}\text { Elevar o IDEB dos anos finais; } \\
\text { Diminuir a distorção idade-série e a } \\
\text { taxa de abandono escolar }\end{array}$ & $\begin{array}{l}\text { Todo o estado concentrando-se } \\
\text { em cidades polos e refletindo o } \\
\text { tamanho da população de } 11 \text { a } 14 \\
\text { anos. }\end{array}$ \\
\hline $\begin{array}{l}\text { Universalização da } \\
\text { educação integral para o } \\
\text { ensino médio. }\end{array}$ & $\begin{array}{l}\text { Ampliar a taxa de escolarização } \\
\text { líquida; Aumentar a média do IDEB; } \\
\text { Reduzir a distorção idade-série e a } \\
\text { taxa de abandono escolar. }\end{array}$ & $\begin{array}{l}\text { Todo o estado concentrando-se } \\
\text { em cidades polos e refletindo o } \\
\text { tamanho da população de } 15 \text { a } 17 \\
\text { anos. }\end{array}$ \\
\hline $\begin{array}{l}\text { Expansão da oferta, do } \\
\text { acesso e da permanência } \\
\text { na educação profissional } \\
\text { e tecnológica. }\end{array}$ & $\begin{array}{l}\text { Ampliar a educação profissional e } \\
\text { tecnológica com qualidade social; } \\
\text { Aumentar o percentual de jovens } \\
\text { matriculados em relação à } \\
\text { população de } 15 \text { a } 24 \text { anos. }\end{array}$ & $\begin{array}{l}\text { Todo o estado concentrando-se } \\
\text { em cidades polos e de acordo } \\
\text { com as vocações econômicas } \\
\text { locais, refletindo o tamanho da } \\
\text { população acima de } 14 \text { anos e } \\
\text { com as carências diferenciadas } \\
\text { no território }\end{array}$ \\
\hline $\begin{array}{l}\text { Ampliação da oferta e do } \\
\text { acesso ao ensino superior. }\end{array}$ & $\begin{array}{l}\text { Aumentar o percentual de jovens de } \\
18 \text { a } 29 \text { anos que frequentam o } \\
\text { ensino superior e ampliar a } \\
\text { participação das pessoas com } 25 \\
\text { anos ou mais com nível superior } \\
\text { completo. }\end{array}$ & $\begin{array}{l}\text { Região Metropolitana do Recife } \\
\text { e interior do estado em } \\
\text { conformidade às necessidades e } \\
\text { vocações locais. }\end{array}$ \\
\hline $\begin{array}{l}\text { Redução significativa do } \\
\text { analfabetismo. }\end{array}$ & $\begin{array}{l}\text { Elevar o percentual de pessoas de } 15 \\
\text { anos ou mais de idade alfabetizadas; } \\
\text { Reduzir o analfabetismo funcional. }\end{array}$ & $\begin{array}{l}\text { Cidades e municípios com maior } \\
\text { concentração de analfabetos e } \\
\text { analfabetos funcionais. }\end{array}$ \\
\hline
\end{tabular}

Fonte: Estratégia de Desenvolvimento de Pernambuco e Carteira de Projetos Públicos (PERNAMBUCO, 2014).

\footnotetext{
${ }^{4}$ Apesar do projeto objetivar a implantação de 184 escolas até 2020, em 2017 o estado contava com a instalação, de forma experimental, de apenas uma escola deste tipo (VERAS, 2017).
} 
A partir dos projetos instituídos espera-se que até 2035, tanto o nível de escolaridade quanto a qualidade da educação em Pernambuco ampliem-se de forma expressiva, o que poderá ocorrer mediante a contribuição do bônus demográfico da população em idade escolar que deve declinar $^{5}$, contribuindo para que se alcancem níveis superiores aos dos melhores estados do país e se aproxime de padrões internacionais.

Os objetivos propostos pelo estado de Pernambuco quanto ao aspecto educacional são amplos em termos demográficos, políticos e territoriais, visto que englobam todas as faixas etárias dos diversos níveis da educação básica, da creche ao ensino médio, até a educação superior, e todas as esferas de gestão da educação nacional, do Município, ao próprio Estado e à União. Territorialmente os planos estatais mostram-se também abrangentes, considerando todo espaço geográfico sob sua jurisdição inclusive sua heterogeneidade, cidades polos e vocações consolidadas, neste sentido, uma das marcas do território pernambucano, sua pluralidade e complexidade em termos regionais, tende a apresentar especificidades quanto às metas propostas que poderão já ter sido alcançadas, serem possíveis de alcance ou dificilmente atingíveis sem a participação de outros entes federativos e do conjunto da sociedade, como é o caso da Microrregião da Mata Meridional.

\section{ASPECTOS DA EDUCAÇÃo NA MICRORREGIÃO DA MATA MERIDIONAL PERNAMBUCANA: UMA AVALIAÇÃO COMPARATIVA}

O Brasil apresenta as mais diversas peculiaridades territoriais sobre vários aspectos, dentre eles a educação. Ao considerar-se os recortes intermediários entre o Estado e o município tal diversidade também se faz presente. Numa escala microrregional, portanto intermediária, torna-se possível agrupar determinado número de municípios e tratar suas semelhanças de forma única, construindo-se um conjunto no qual é possível constatar a existência de certa uniformidade interna e compará-la à diferentes esferas.

A Microrregião da Mata Meridional Pernambucana instituída pelo IBGE é formada por vinte e um municípios (Mapa 1), marcada por antiga ocupação humana, que remete à história colonial brasileira de instalação da monocultura da cana-de-açúcar, e por índices

\footnotetext{
${ }^{5}$ Segundo o próprio documento, entre 2010 e 2035, a população de crianças na primeira infância, com idade para creche, deve cair de 786 mil para 569 mil, já o quantitativo de crianças com idade para os anos iniciais do ensino fundamental, deve reduzir-se de 846 mil para 596 mil e para os anos finais a diminuição é de 833 mil para 622 mil. O ensino médio deverá sofrer uma redução de 811 mil alunos para 646 mil (PERNAMBUCO, 2014).
} 
socioeconômicos inferiores à realidade pernambucana e nacional. Neste contexto, os índices de educação, são significativos quanto à "distância" socioeconômica da Microrregião frente a outras escalas. Tomando-se, por exemplo, o aspecto "Educação" do Índice de Desenvolvimento Humano (IDH), a Microrregião em 2010 registrava o valor de 0,477 , inferior ao do próprio estado (0,574) e do Brasil (0,637) (PNUD, 2018).

Mapa 1 - Mata Meridional Pernambucana, localização e composição municipal

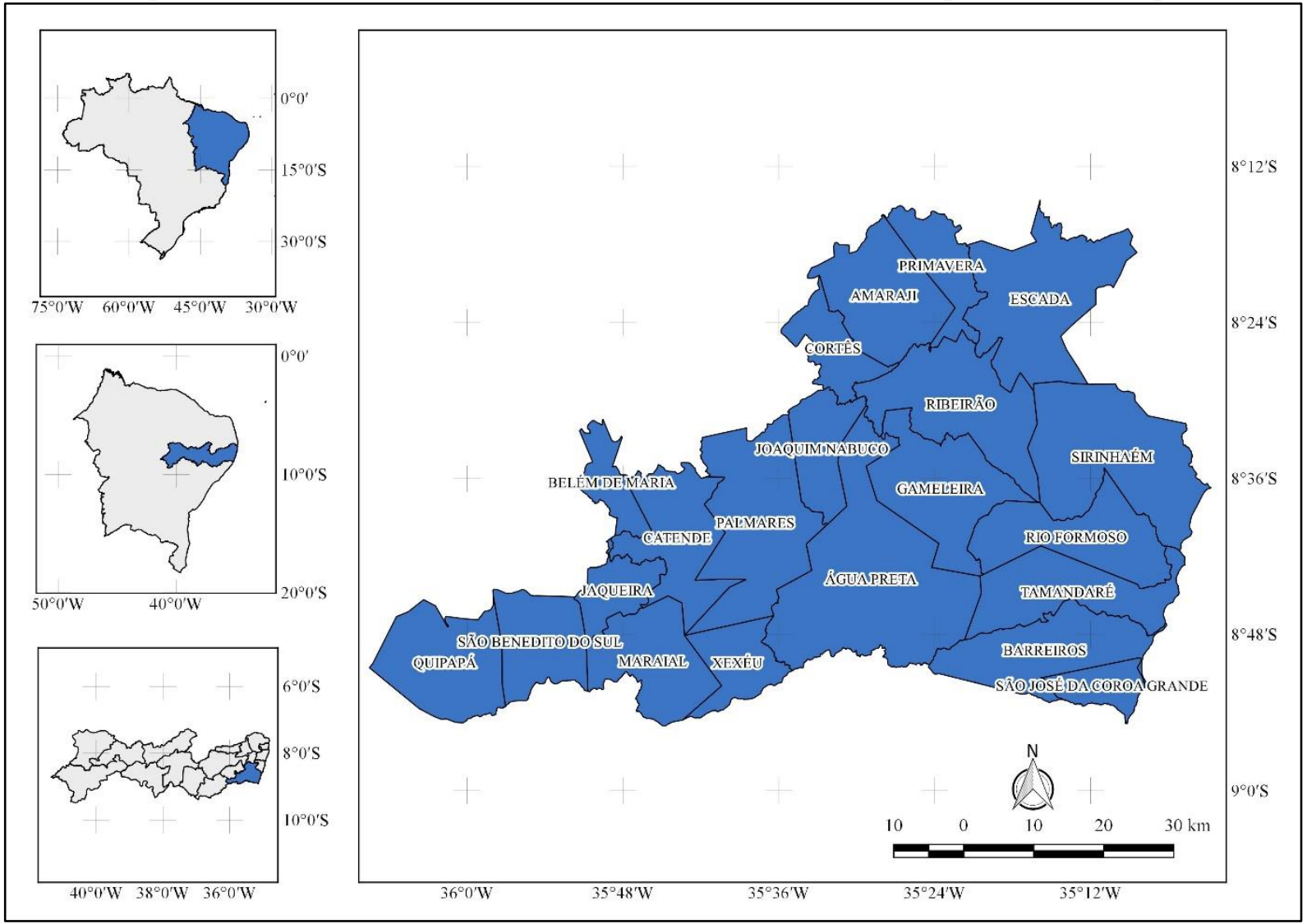

Fonte: Elaborado pelo autor.

A partir da ordem de apresentação dos projetos da área de resultado "Educação e Conhecimento" (Quadro 1) estabelecida na Estratégia de Desenvolvimento de Pernambuco e Carteira de Projetos Públicos (PERNAMBUCO, 2014) e, principalmente, sua correlação com informações disponibilizados pelo Atlas do Desenvolvimento Humano no Brasil (PNUD, 2018), serão expostos a seguir os dados quantitativos em relação à educação nas escalas microrregional, estadual e nacional para posterior abordagem qualitativa do seu significado.

Quanto à ampliação da oferta, acesso e qualidade na educação infantil, o atendimento pré-escolar em 2010 na Microrregião mostrava-se inferior ao das demais esferas. Enquanto 
naquela 38,29\% das crianças de 0 a 5 anos eram atendidas pela educação infantil em creches e pré-escolas, em Pernambuco tal valor era de 43,23\% e no Brasil, 43,15\% (PNUD, 2018).

No que se refere à melhoria da qualidade do ensino fundamental, é possível considerala em dois aspectos: frequência e êxito. Em 2010 na Microrregião 94,71\% da população entre 6 e 14 anos frequentava o ensino fundamental, valor próximo ao registrado no estado $(96,35 \%)$ e no Brasil (96,69\%), contudo, a porcentagem desta população com dois anos ou mais de atraso em 2010 era superior na Microrregião (22,89\%), comparativamente a Pernambuco (18,88\%) e ao país (15,9\%) (PNUD, 2018). Ao considerar-se a porcentagem da população de 15 a 17 anos ainda no ensino fundamental regular seriado em 2010, a Microrregião apresentava dados superiores aos do estado e do Brasil, enquanto naquela o valor era de 39,83\%, no estado tal valor era 33,3\% e no Brasil, 27,11\%, por sua vez, ao analisar-se a população de 18 a 24 anos na mesma situação em 2010, a realidade microrregional mostrava-se também pior que nas outras esferas: na Microrregião 7,67\% da população estava nesta condição, enquanto que no estado tal valor era de 5,06\% e no Brasil, 3,41\% (PNUD, 2018). Pode-se observar, portanto, que é a falta de qualidade no ensino fundamental, constatada mediante a repetência escolar, que ainda funciona como uma barreira à universalização do ensino obrigatório em várias esferas (MELLO, 1991).

Quanto ao Índice de Desenvolvimento da Educação Básica ${ }^{6}$ (IDEB), em 2015, a Microrregião conseguiu superar a meta estabelecida quanto aos anos iniciais do ensino fundamental, porém, não conseguiu atingi-las quanto aos anos finais desta etapa de ensino. Comparativamente a Pernambuco, a Microrregião mostra-se num patamar inferior visto que aquele conseguiu atingir as metas propostas. Considerando-se a escala nacional, a Microrregião mostra-se numa posição equivalente, visto que o Brasil também não conseguiu atingir as metas propostas quanto aos anos finais do ensino fundamental ${ }^{7}$. Tomando apenas os números, é possível constatar que os dados da Microrregião foram inferiores ao do estado e do Brasil tanto para os valores alcançados como para os projetados para o ano de 2015 (Tabela 1).

\footnotetext{
${ }^{6}$ Criado em 2007, pelo Instituto Nacional de Estudos e Pesquisas Educacionais Anísio Teixeira (INEP), o IDEB mede a qualidade do aprendizado nacional a partir do cálculo da taxa de aprovação (rendimento escolar) e das médias de desempenho na Prova Brasil, para escolas e municípios, e no Sistema de Avaliação da Educação Básica (SAEB) para os estados e o país. As metas estabelecidas para o índice, apesar de diferenciadas para cada escola e rede de ensino, visam alcançar 6 pontos até 2022, média que corresponde ao sistema educacional dos países desenvolvidos (BRASIL, MINISTÉRIO DA EDUCAÇÃO, 2018).

7 "Exame rigoroso da situação do ensino fundamental no Brasil revela, hoje [1991], que o acesso a esse ensino está praticamente universalizado. Nossas crianças chegam à escola. O problema é que, apesar de nela permanecerem por um período de tempo suficiente para terminar o $1^{\circ} \mathrm{Grau}$, devido a fatores internos àquela e não - como costuma afirmar o senso comum - por causa de suas condições materiais de vida, abandonam-na antes de terminar o curso" (MELLO, 1991, p. 16).
} 
Tabela 1 - Índice de Desenvolvimento da Educação Básica (IDEB), Áreas selecionadas, 2015

\begin{tabular}{lcccc}
\hline & \multicolumn{2}{c}{ Anos Iniciais } & \multicolumn{2}{c}{ Anos Finais } \\
\cline { 2 - 5 } & Valor alcançado & Valor projetado & Valor alcançado & Valor projetado \\
\hline Microrregião & 4,3 & 4,2 & 3,5 & 4 \\
\hline Pernambuco & 4,6 & 4,2 & 3,8 & 3,6 \\
\hline Brasil & 5,5 & 5,2 & 4,5 & 4,7 \\
& & Fonte: INEP, 2018.
\end{tabular}

Tratando-se da implementação das escolas com educação integral nos anos finais do ensino fundamental II, parte-se do pressuposto da existência de infraestrutura para isso, neste sentido, observa-se que em 2015 toda a Microrregião possuía 668 estabelecimentos de ensino fundamental (8,6\% do total do estado), menos que o município do Recife, que abrigava sozinho 739 estabelecimentos (9,5\% de todo estado) (IBGE CIDADES, 2018).

Considerando-se a universalização da educação integral para o ensino médio, observase que a taxa de frequência líquida ao ensino médio regular seriado em 2010 da população entre 15 e 17 anos na Microrregião era de 28,66\%, valor inferior à do estado (35,3\%) e do Brasil $(43,38 \%)$. A porcentagem de população de 18 a 24 anos ainda no ensino médio regular seriado em 2010, portanto em distorção idade-série, era semelhante na Microrregião e no estado: 8,81\% e $8,01 \%$ respectivamente, ambos superiores ao Brasil, 6,89\% (PNUD, 2018).

Em toda Microrregião já em 2015 existiam escolas estaduais de referência em ensino médio ofertando educação integral, principalmente em regime de 35 horas semanais (semiintegral) (PERNAMBUCO, SECRETARIA DE EDUCAÇÃO, 2018a).

A expansão da oferta, do acesso e da permanência na educação profissional e tecnológica é um desafio para o estado na Microrregião, sobretudo quanto à expansão da oferta, visto que, em 2015, apenas dois municípios contavam com escolas técnicas estaduais ofertando cursos profissionalizantes (PERNAMBUCO, SECRETARIA DE EDUCAÇÃO, 2018b).

A ampliação da oferta e do acesso ao ensino superior configura-se como outro desafio para o estado: dos vinte e um municípios da Microrregião, há instituições de ensino superior em apenas sete deles, dentre estes, cinco o oferecem em rede exclusivamente privada e apenas dois o ofertam em rede privada e pública em instituições municipais, estaduais e/ou federais (BRASIL, MINISTÉRIO DA EDUCAÇÃO, 2018), o que, reflete na baixa porcentagem de pessoas com 25 anos ou mais com ensino superior completo, quando, em 2010, tal valor era de 11,27\% para o Brasil e 8,01\% para o estado, na Microrregião era de 3,07\% (PNUD, 2018).

\begin{tabular}{lll}
\hline Barbosa, 2019 & ISSN 0104-5490
\end{tabular}


Por fim, a redução significativa do analfabetismo surge como uma medida de caráter emergencial na Microrregião que apresenta índices superiores ao do Brasil e do estado em todas as faixas etárias, destacando-se a população entre 25 e 29 anos, na qual a taxa de analfabetismo era, em 2010 , de $16,11 \%$, valor extremamente alto comparativamente à do estado $(8,94 \%)$ e principalmente à do Brasil (3,96\%) (PNUD, 2010).

Diante do exposto é possível observar que a Microrregião da Mata Meridional Pernambucana como um todo encontra-se em patamares educacionais inferiores ao estado de Pernambuco e ao Brasil. Considerando esses dados mediante a atual conjuntura socioeconômica global e mesmo nacional e tomando como ponto de partida o ambicioso projeto de desenvolvimento elaborado pelo governo estadual para 2035, pode-se questionar a viabilidade deste projeto para a Microrregião.

\section{CONSIDERAÇÕES FINAIS}

A revolução tecnológica trouxe diferentes demandas para a sociedade ao promover a inovação quanto aos produtos e à necessidade de mão de obra cada vez mais qualificada para a produção dos novos bens e a operação dos equipamentos desenvolvidos. A educação neste novo contexto apresenta-se como um setor de grande valor ao assumir a responsabilidades de qualificar os recursos humanos seja para a economia, seja para a vida na complexa e interconectada sociedade fruto, dentre outros, das novas tecnologias de comunicação.

O setor educacional, apesar de importante para o desenvolvimento econômico, pontualmente é por ele trabalhado e planejado de forma ampla e direta. O Estado é o agente responsável pela promoção da educação em várias sociedades atuando tanto como planejador e regulador mediante a instituição de normas e metas, como promotor direto deste serviço a partir da manutenção de infraestrutura e mão de obra própria.

Desenvolvimento e educação são elementos inter-relacionados que na esfera privada e pública assumem escalas diferenciadas. Para a iniciativa privada a educação é um serviço que deve gerar lucro ou oferecido para produzir lucro mediante, por exemplo, a capacitação e profissionalização da mão de obra, neste contexto, predomina a promoção do desenvolvimento, ou melhor, do crescimento econômico. Quanto à esfera pública, o setor educacional assume uma escala superior quantitativamente, por direcionar-se às mais diversas populações e faixas etárias, e qualitativamente, quando volta-se para a formação humana para a vida em sociedade, 
para o desenvolvimento humano em outras esferas: social, política, cultura, ambiental e, também, econômica.

Planejar políticas públicas para a educação em âmbito estatal é algo mais complexo, demanda sua relação com outros elementos que compõem a sociedade e com sua diversidade, complexidade e, sobretudo, desigualdade quando, mediante valores numéricos, é possível constatar a coexistência espaçotemporal de realidades que destoam significativamente entre si e que não cabem facilmente nos projetos pensados e nas metas estabelecidas.

A Microrregião da Mata Meridional Pernambucana é certamente uma realidade espacial que insere-se dificilmente nos projetos estaduais de desenvolvimento da educação pensados para os próximos anos. Partindo-se da escala brasileira, um país emergente, que apresenta significantes índices econômicos mas que mostra-se aquém quanto aos índices de desenvolvimento humano, como a educação; perpassando-se pela escala estadual, um ente político-administrativo que apresenta um quadro socioeconômico ainda inferior ao do país; chega-se à Microrregião em tela, com índices educacionais ainda mais baixos e desafiadores.

Tomando como base os reduzidos valores quanto aos índices de educação da Microrregião diante das outras esferas comparativas em praticamente todos os aspectos observados em 2010 e os baixos Índices de Desenvolvimento da Educação Básica de 2015 quanto aos valores alcançados e projetados diante das esferas estadual e brasileira, é possível concluir que as políticas públicas instituídas na esfera estadual e implementadas territorialmente na escala microrregional possuem capacidade de sucesso muito mais limitada.

Implementar políticas públicas considerando as singularidades regionais quanto ao tamanho e faixa etária da população e suas carências é uma iniciativa salutar, porém, é preciso não considerar somente a existência de cidades polos para a implementação de tais políticas em virtude do risco de ampliação das concentrações e desigualdades, assim como considerar a vocação econômica local, que não reflete em melhores índices de desenvolvimento humano, é cristalizar o quadro de subdesenvolvimento regional. As políticas públicas na Microrregião, dentre elas a de educação, têm a dupla tarefa de promover o quanto antes a qualidade de vida das pessoas e dinamizar o quadro socioeconômico local. Este é o grande e urgente desafio.

\section{REFERÊNCIAS}

BRASIL. Instituto Brasileiro de Geografia e Estatística - IBGE. Cidades. Disponível em: <https://cidades.ibge.gov.br/>. Acesso em 08 jul. 2018. 
Instituto Nacional de Estudos e Pesquisas Educacionais Anísio Teixeira - INEP. Índice de Desenvolvimento da Educação Básica - IDEB. Disponível em: <http://ideb.inep.gov.br/resultado/home.seam?cid=1846787>. Acesso em 07 jul. 2018.

Ministério da Educação. E-MEC. Instituições de Educação Superior e Cursos Cadastrados. Disponível em: <http://emec.mec.gov.br/>. Acesso em 08 jul. 2018.

IDEB - Apresentação. Disponível em: <http://portal.mec.gov.br/secretariade-educacao-basica/programas-e-acoes?id=180>. Acesso em 07 jul. 2018.

Projeto Brasil 3 Tempos. Núcleo de Assuntos Estratégicos da Presidência da República (NAE). N. 6. Brasília: 2006. Disponível em: <http://www.biblioteca.presidencia.gov.br/publicacoes-oficiais/catalogo/lula/projeto-brasil-3tempos-nae-cen>. Acesso em 09 jul. 2018.

FAVARO, Neide de Almeida Lança Galvão; TUMOLO, Paulo Sérgio. A relação entre educação e desenvolvimento econômico no capitalismo: elementos para um debate. Revista Educação \& Sociedade. Volume 37. N. 135. Campinas, maio / jun. 2016. Disponível em: <http://www.scielo.br/pdf/es/v37n135/1678-4626-es-37-135-00557.pdf>. Acesso em: 06 jul. 2018.

MELLO, Guiomar Namo de. Políticas públicas de educação. Estudos Avançados. Volume 5. N. 13. São Paulo. Set. / Dez. 1991. pp. 7-47. Disponível em: <http://www.scielo.br/pdf/ea/v5n13/v5n13a02.pdf>. Acesso em: 06 jul. 2018.

PERnAmbuCO. Estratégia de Desenvolvimento e Carteira de Projetos Públicos Pernambuco 2035. Disponível em: $<$ https://drive.expresso.pe.gov.br/s/LkFODyou3WwuUQc/download>. Acesso em: 06 jul. 2018 .

Secretaria de Educação. Secretaria Executiva de Educação Profissional. Dados das 300 escolas. Disponível em: <http://www.educacao.pe.gov.br/portal/upload/galeria/560/Educacao_Integral_RELACAO_3 00_EREM_2015.pdf>. Acesso em: 08 jul. 2018a.

em:

. Educação Profissional. Relação das Escolas Técnicas Estaduais. Disponível <http://www.educacao.pe.gov.br/portal/upload/galeria/1210/RELACAO_28_ETE_2015.pdf>. Acesso em: 08 jul. $2018 b$.

PNUD - PROGRAMA DAS NAÇÕES UNIDAS PARA O DESENVOLVIMENTO. Atlas do Desenvolvimento Humano no Brasil. Disponível em: <http://atlasbrasil.org.br/2013/pt/consulta/>. Acesso em: 06 jul. 2018.

SAVIANI, Demerval. Interlocuções pedagógicas: conversa com Paulo Freire e Adriano Nogueira e 30 entrevistas sobre educação. Campinas: Autores Associados, 2010. (Coleção memória da educação) 
STEINER, João E. Conhecimento: gargalos para um Brasil no futuro. Estudos Avançados. Volume 20. N.56. São Paulo, Jan./Abr. 2006. Disponível em: <http://www.scielo.br/pdf/ea/v20n56/28628.pdf>. Acesso em: 06 jul. 2018.

VERAS, Paulo. Pernambuco levará educação integral para Ensino Fundamental. Jornal do Commercio. Recife, 28 jun. 2017. Disponível em: <http://jconline.ne10.uol.com.br/canal/politica/pernambuco/noticia/2017/06/28/pernambucolevara-educacao-integral-para-ensino-fundamental-292094.php>. Acesso em: 08 jul. 2018. 